\section{O Brasil na Era Lula: retorno ao desenvolvimentismo?}

\section{Palavras-chave \\ economia brasileira, desenvolvimentismo, crise financeira global}

Classificação JEL O1, E6, B5

\section{Key-Words}

Brazilian economy,

developmentalism, global

financial crisis

JEL Classification $O 1, E 6, B 5$

Pedro Cezar Dutra Fonseca Professor Titular do Departamento de Economia e Relaçôes Internacionais da UFRGS e Pesquisador do CNPq - Brasil. André Moreira Cunha Professor Associado do Departamento de Economia e Relaçóes Internacionais da UFRGS e Pesquisador do CNPq - Brasil.

Julimar da Silva Bichara Professor da Universidade Autónoma de Mardrid - Espańa e Diretor do Centro de Estudios Brasileńos Fundación Ortega y Gasset.

\section{Resumo}

$\mathrm{O}$ artigo retoma variáveis sobre o desempenho recente da economia brasileira com o propósito de enfocar a questão se, a partir dessa análise conjuntural, pode-se detectar que o país estaria resgatando, sob nova roupagem, uma matriz de políticas desenvolvimentistas. Para ensaiar resposta à questáo, parte-se de uma análise sobre o desempenho recente da economia e da contextualizaçáo do referido debate para, por fim, elaborar um contraponto entre o governo Lula e os traços estruturais da experiência histórica da economia brasileira no período que ficou conhecido na literatura como "era do desenvolvimentismo", esta entendida como cinco décadas, a partir de 1930, de elevado crescimento e de modernização do país.

\section{Abstract}

This paper analyzes some variables connected to the recent performance of the Brazilian economy in order to assess whether, under this conjunctional analyses, it can be detected that the country returned to a new matrix of developmentalist policies. An analysis is examined regarding the recent performance of the economy and the contextualization of the mentioned debate. Next, a comparison is made between the Lula administration and the structural features of the historical experience of the Brazilian economy during the period referred to in the literature as "the developmentalism era". This era comprehended five decades as of 1930 , which presented an elevated growth and a modernization of the country. 


\section{Introdução: retomada de uma trajetória?}

Este artigo propóe-se a contribuir para o debate sobre duas questóes suscitadas pelo desempenho recente da economia brasileira, o qual vem dividindo a literatura, e que sugere novamente uma trajetória de navegar contra a corrente das economias hegemônicas, embora desta vez em companhia de alguns países tidos como "emergentes", como China, Índia, Rússia, África do Sul, dentre outros (Goldman Sachs, 2007). A primeira questão, mais voltada à conjuntura, remete às condiçóes permissivas à manutençáo dessa tendência de crescimento e aos prováveis percalços que poderão antepor-se como seus fatores limitantes. A segunda estende a anterior a um questionamento de longo prazo e exige, metodologicamente, uma reflexão histórica: estaria o país retomando, embora em nova forma, as teses e as políticas desenvolvimentistas que nortearam o comportamento de governos e de policy makers no Brasil a partir de 1930 - possivelmente mais do que em qualquer outro país latino-americano? Estas teriam saído de cena nas duas últimas décadas do século XX, diante do agravamento da crise fiscal do Estado, do balanço de pagamentos e da inflação, quando cederam espaço às propostas mais afinadas com o neoliberalismo ${ }^{1}$, centradas na busca da estabilidade macroeconômica, críticas à substituição de importaçóes, ao planejamento econômico e à prioridade ao desenvolvimento.

Atualmente se registra uma controvérsia sobre o desempenho da economia brasileira a partir do Governo Lula (2003-2010). De um lado, vários economistas, e o próprio discurso oficial, enfatizam o que consideram ser altas taxas de crescimento, principalmente se forem levados como padrão de comparação os oito anos anteriores, do Governo Fernando

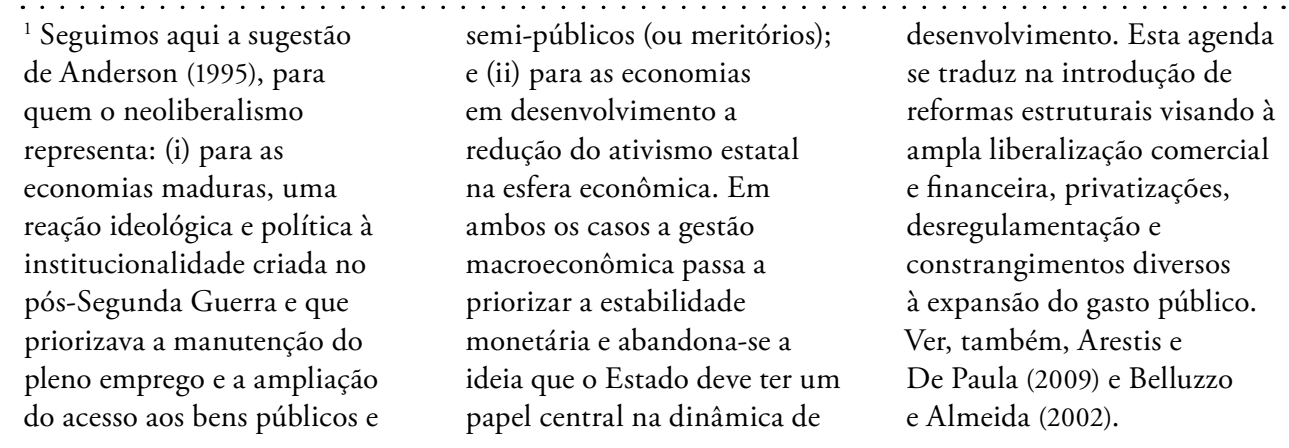


Henrique Cardoso, e, mais recentemente, a crise financeira global que se apresentou de forma mais nítida a partir de 2008. Em decorrência, vários autores têm sugerido a interpretação de que estaria de volta o desenvolvimentismo brasileiro, ressaltando mudanças na condução da economia com relação aos governos das décadas de 1980 e 1990 (ver, por exemplo: Belluzzo: 2009; Novy: 2009a, 2009b; Nakano: 2010; Cervo: 2009; Herrlein: 2011; Cardoso Jr., 2011, p. 61, 450). Outros, concordando com a guinada de rumo, mas de forma crítica ao lamentar o abandono da ortodoxia pelos ímpetos redistributivistas que o governo manifestaria, como se mostrará adiante, admitem as tendências desenvolvimentistas do governo Lula e as interpretam como uma forma de populismo, lembrando a antiga relação, tradicional nas análises sobre economia latino-americana, desenvolvimentismo, substituição de importações e populismo.

$\mathrm{Na}$ defesa da opçáo pelo desenvolvimento, os autores lembram principalmen-

2 "Desde 2005, a inflação, medida pelo IPCA, mantêmse dentro das bandas do regime de metas da inflação. A forte recuperação econômica de 2010, na qual a demanda interna cresceu $10,3 \%$, foi compatível com o cumprimento do te que, em 2010, a economia brasileira cresceu $7,5 \%$, acima do que mercado e governo projetavam quando a crise financeira global fez com que a renda experimentasse uma pequena contração em 2009. Mesmo a partir de diferentes fontes, compartilhava-se a crença de que "sólidos fundamentos macroeconômicos" alcançados gradualmente nas últimas décadas lastreiam as expectativas otimistas quanto às perspectivas do país e lhe asseguram realismo. A inflação, tradicionalmente o maior problema das políticas de estabilização na segunda metade do século XX, manteve-se baixa, tendo o IGP-DI/FGV fechado o ano de 2009 com a inédita taxa de $-1,43 \%$, a primeira deflação anual em sua série histórica. Mesmo com a aceleração nos preços a partir de meados de 2010, a inflação tem-se situado próxima aos limites determinados pelo Sistema de Metas (Ministério da Fazenda, 2011) ${ }^{2}$. Outra vulnerabilidade recorrente, o desequilíbrio externo, também sugere ser coisa do passado $^{3}$ : a conta capital e financeira atingiu o superávit recorde de US\$111,9 bilhóes em 2011 (4,5\% do PIB), mais do que superando o déficit em conta corrente de US\$ 52,6 bilhóes (2,1\% do PIB). Assim, em um contraste marcante com o passado, a entrada excessiva de capitais que pressiona a moeda nacional no sentido de sua apreciação tem sido considerada 
um dos principais desafios macroeconômicos. As reservas internacionais atingiram o patamar de US\$ 288,5 bilhóes em dezembro de $2010^{4}$, volume inimaginável para quem inúmeras vezes precisou recorrer ao FMI a partir da década de 1980 e que tinha na dívida externa uma de suas variáveis mais frágeis, capaz de sugerir em inúmeras ocasióes a possibilidade de moratória. De fato, desde 2007 o país apresenta uma dívida externa líquida negativa, que em termos proporcionais ao PIB atingiu a cifra de $-2,5 \%$ em 2010 (Ministério da Fazenda, 2011, p. 104).

Por outro lado, não é de menor vulto e menos incisiva a literatura que aponta para direção diametralmente oposta. Já em 2005, Paula (2005, p.7) argumentava contrariamente ao caráter desenvolvimentista, apontando mais continuidades que ruptura com relação ao governo anterior: um continuísmo neoliberal. $\mathrm{Na}$ mesma direção manifestaram-se outros autores como Borges Neto (in Paula, 2005), que inclusive procura desvendar as forças políticas e econômicas de sustentação ao governo, concluindo que o mesmo poderia ser considerado avesso ao desenvolvimentismo e mais comprometido com o "social-liberalismo". Carvalho (2007), por sua vez, salienta que as políticas monetárias e cambiais seguem as regras da ortodoxia e que mesmo instrumentos que não exigi- riam "maior dramaticidade na sua adoção", como controle de capitais, não foram adotados. Mas mesmo antes desses, Paulani (2003), argumentava que a prioridade de combate a inflaçáo do governo Lula seguia a cartilha ortodoxa ao considerar a inflação como de demanda, cuja conseqüência era diminuir o crédito e os investimentos; a sobrevalorização do real poderia ser interpretada como uma estratégia anticrescimento e requeria o ingresso de capitais de curto prazo, via altas taxas de juros, para assegurar certo equilíbrio no balanço de pagamentos. Em artigos posteriores (Paulani, in Sicsú et alli, 2005; Paulani e Pato, in Paula, 2003; 2007), é reafirmada a opção ortodoxa do governo Lula, cuja política econômica seria mais comprometida com a valorização financeira do que com o crescimento e com a distribuiçáo de renda; Lula não teria apenas continuado, mas aprofundado a "herança maldita" do governo Fernando Henrique Cardoso. Na mesma obra (Sicsú et alli, 2005, p. 91), Assis corrobora a mesma tese ao argumentar que a centralidade do diagnóstico de inflação de demanda na formulação da política econômica impóe uma política monetária com "custos sociais intoleráveis, em termos de recessão e desemprego". Mais recentemente, Gonçalves (2012), na mesma direção, ponderou
${ }^{4}$ Pelo conceito de liquidez internacional. Para se colocar em perspectiva, estes valores atingiram, respectivamente, US\$ 355 bilhôes, em dezembro de 2011, e US\$ 365 bilhóes, em março de 2012. Ver: www.ipeadata.gov.br, acesso em 18/05/2012. 
que o governo Lula poderia ser considerado um "nacional-desenvolvimentismo às avessas": enquanto o primeiro optara pela industrialização via substituição de importaçóes, melhoria do padrão de comércio, maior controle nacional do sistema produtivo e subordinação da política monetária à política de desenvolvimento, dentre outras medidas, a política econômica do período de Lula apontaria em direção diametralmente oposta: desindustrialização, reprimarização das exportações, desnacionalização e dominação financeira sobre a esfera produtiva.

A proposta deste artigo, para ensaiar repostas às questóes inicialmente formuladas, vai na direção de buscar uma mediação entre as duas correntes as quais, sumariamente, sintetizamos como em lados opostos na controvérsia, em caminho semelhante ao de Morais e Saad-Filho (2011). Estes, partindo da polaridade entre "ortodoxia convencional" e "novo desenvolvimentismo", com base na tipologia elaborada por Bresser-Pereira (2006, 2011a) e Sicsú, Paula e Michel (2005), procuram mostrar que o governo Lula foge a qualquer classificação a priori entre "governo neoliberal" versus "governo desenvolvimentista”, e que o mesmo realizou, com êxito e embora lentamente, uma política "híbrida", inclusive ao colocar em prática várias políticas recomenda- das pelo "novo-desenvolvimentismo". Antes que aprofundar a questão em torno do hibridismo, nossa opção foi partir de uma conceituação de desenvolvimentismo (seção 2) - passo metodológico necessário, pois se trata de termo cuja definição sempre comporta polêmica. Para tanto, avalia-se o desempenho recente da economia brasileira (seção 3), o qual, tendo como referencial o marco analítico da seção 2 e a discussão em torno do populismo econômico, permite-nos contribuir com o debate (seção 4) sugerindo que: (i) o período que se inaugura com o Governo Lula não pode ser facilmente enquadrado como sendo populista; mas, também, (ii) embora haja indícios para sua defesa, não estão claramente consolidadas as condiçóes para a sustentação do desenvolvimentismo como base ideológica da retomada recente de certo dinamismo econômico.

\section{2_O Desenvolvimentismo no Brasil: uma primeira aproximação}

A possibilidade de crescer em plena crise internacional e de recuperações rápidas náo constitui novidade e integra o imaginário de boa parte dos economistas e das elites brasileiras. Assim ocorrera na Grande Depressão da década de 1930, quando a reversão do ciclo recessivo deu-se já em 
1932, com taxa de 4,3\% do PIB, e 9,0\% em 1933 - período mais trágico para a maior parte dos países, auge da depressão norte-americana. Consagrou-se a clássica interpretação de Celso Furtado de que o Brasil antecipara na prática as políticas keynesianas, como resultado de o governo Vargas ter incitado os produtores a colherem o café, principal item da pauta de exportaçóes, e responsabilizado-se por assegurar preço através da compra e queima de parte do produto, com financiamento ancorado em emissão de moeda. Mais que a precoce recuperação, a crise colaborou para que a economia brasileira passasse por uma inflexão estrutural, com a superação do modelo agroexportador, centrado na venda para o mercado externo de poucos produtos primários, e alterasse seu "centro dinâmico" em favor da indústria e do mercado interno, dando início ao processo de substituição de importaçóes: de 1933 a 1939 a indústria brasileira cresceu numa média de 11,2\% ao ano (Furtado, 1977: 192). Já em outra conjuntura externa adversa, no início da década de 1970, com o primeiro choque do petróleo, o governo militar - mesmo que avesso ao que denominava populismo e esquerdismo de Vargas e de seus sucessores, afastados pelo golpe de estado de 1964 -, procedeu de forma semelhante. Ao invés de ajustar-se à conjuntura atra- vés do recatado receituário ortodoxo que aconselhava diminuir o ritmo de atividade econômica diante da elevação das taxas internacionais de juros e dos preços do petróleo em quatro vezes, o governo propôs acelerar o processo de substituição de importações para os ramos da indústria pesada de bens intermediários e de capital, além de incentivar, através de empresas estatais, megainvestimentos na área energética, os quais acenavam no longo prazo para menor dependência do exterior com relação ao petróleo importado. Mesmo que tenha jogado o custo do ajuste para o futuro, o crescimento brasileiro entre e 1974 e 1980 manteve uma taxa anual em torno de $7 \%$, bastante superior à média internacional; em três anos - 1974, 1976 e 1980 - alcançou o patamar de $9 \%$.

Ao assumir em 2002, o presidente Lula manteve não só alguns marcos essenciais da política econômica em prol da estabilidade do governo Fernando Henrique Cardoso (metas de inflação, taxa de câmbio flexível e valorizada, superávit primário), mas ampliou vários programas de assistência social. A implementação das teses de focalização das políticas sociais iniciadas por este último, críticas à universalização dos direitos, aos moldes da antiga Social-Democracia, graças a essa expansão ganhou um status de quase universalidade: 
só o Programa Bolsa-Família ${ }^{5}$ foi estendido a 11 milhões de famílias ${ }^{6}$, quase triplicando sua abrangência. $\mathrm{O}$ salário mínimo cresceu 57\%, em termos reais, entre 2002 e $2010^{7}$, atingindo o maior patamar desde o começo dos anos 1970, quando do chamado "Milagre Brasileiro", o que significou um acréscimo significativo da massa salarial e do consumo de bens-salário? Já o coeficiente de Gini caiu de 0,596 para 0,543 entre 2001 e 2009, a evidenciar certa consistência na reversão da tendência crescente verificada até meados dos anos 1990. Como consequência, detecta-se certa distensão no tradicionalmente concentrado e excludente crescimento brasileiro. O mercado interno mostrou-se, em 2009, como válvula de escape ao pífio desempenho do setor exportador, pressionado pe- la crise internacional e pela apreciação do real: mesmo com o PIB estagnado, estatísticas registram a criação de cerca de $1 \mathrm{mi}$ lhão de empregos formais no ano, e sugerem o papel relevante do mercado interno e do consumo doméstico para o alcance deste resultado (Ministério da Fazenda, 2010 e 2011).

Por outro lado, o Programa de Aceleração do Crescimento (PAC), mesmo que ainda com tímidos resultados, acena à retomada de sua responsabilidade como indutor do crescimento, ao priorizar setores e diagnosticar gargalos para o crescimento de longo prazo, com previsão de investimentos, estatais ou privados, incentivos fiscais e crédito através de órgãos oficiais, como Banco Nacional de Desenvolvimento Econômico e Social (BNDES),
(PBF) é um programa de
transferência direta de renda
com condicionalidades, que
beneficia famílias em situaçáo
de pobreza (com renda mensal
por pessoa de $\mathrm{R} \$ 70$ a $\mathrm{R} \$$
140) e extrema pobreza (com
renda mensal por pessoa de
até $\mathrm{R} \$ 70$ ), de acordo com a
Lei 10.836 , de 09 de janeiro
de 2004 e o Decreto $\mathrm{n}^{\circ} 5.209$, de 17 de setembro de 2004."

(http://www.mds.gov.br/

bolsafamilia/o_programa_

bolsa_familia/o-que-e, acesso

em março de 2010).

${ }^{6}$ Ver: http://www.mds.gov. br/bolsafamilia/o_programa_ bolsa_familia/principaisresultados (acesso em março de 2010).

\author{
${ }^{7}$ Ministério da Fazenda \\ (2011, p. 40). \\ ${ }^{8}$ Ver: "Panorama da \\ Economia Brasileira - \\ superando a crise", em 15 \\ agosto de 2009. Apresentação \\ do Ministro da Fazenda, \\ Guido Mantega (http://www. \\ fazenda.gov.br/portugues/ \\ docs/perspectiva-economia- \\ brasileira/link.htm, acesso em \\ março de 2010).
}

\footnotetext{
${ }^{9}$ De acordo com a Fundação Getúlio Vargas, a classe "C" brasileira, que, em 2003, representava $37 \%$ do total da população, passou a representar $64 \%$ da populaçáo em 2008 (Ministério da Fazenda, 2010). Para uma análise político-sociológica sobre esses novos segmentos, veja: Singer (2010).
} 
Caixa Econômica Federal e Banco do Brasil. Os bancos brasileiros passaram relativamente incólumes pela atual crise, assim como grandes empresas, a exemplo de Petrobras, Vale do Rio do Doce, Gerdau, Embraer, dentre outras. Todos esses fatores somados criam um clima favorável, o qual se associa a eventos simbólicos na área externa, com o crescimento dos investimentos das empresas brasileiras no exterior (de cerca de US\$ 1 bilhão anuais nos últimos anos da década de 1990 para em torno de US\$ 25 bilhóes em 2006-2008) e a presença maior do país em acontecimentos midiáticos (Conferência do Clima em Copenhage, tropas no Haiti, conquista de sede das Olimpíadas e da Copa do Mundo).

Os autores que interpretam o governo Lula como uma retomada, mesmo em nova forma, do desenvolvimentismo, tendem a argumentar, implícita ou explicitamente, que este pode, via de regra, ser entendido como fenômeno embedded na formação social brasileira, com raízes históricas profundas, de modo que o interregno das duas últimas décadas do século XX pode ser visto como a interrupção temporária de uma tendência que, mediante certas condições permissivas, aflora novamente. Essas interpretaçóes convergem para a hipótese aqui defendida segundo a qual não foi apenas a crise que ensejou condiçóes para a mudança, como nas conjunturas anteriormente mencionadas das décadas de 1930 e 1970; a retomada, mesmo que gradual, de um ciclo de crescimento econômico e a incorporaçấo de novos segmentos da população ao mercado consumidor, induzidas em parte pela politica governamental e em parte pelo contexto internacional, já se manifestavam anteriormente como tendência. O exercício de partir de dados da conjuntura para delinear cenários sempre se mostra desafiador ao economista, ainda mais quando associado a uma reflexão histórica em busca de encontrar elementos de ruptura e/ou continuidade a marcos estruturais institucionalmente arraigados. Por isso, fazem-se necessárias algumas consideraçôes sobre o significado histórico do desenvolvimentismo brasileiro, a fim de que a discussão sobre a conjuntura atual não se esgote em si mesma e possa sugerir caminhos para uma reflexão sobre possíveis trajetórias de longo prazo.

Não há dúvida de que o desenvolvimentismo latino-americano como objeto de investigação é tema complexo ${ }^{10}$. Trata-se de conceito muitas vezes escorregadio, pois abarca situações históricas distintas e multifacetadas. Mesmo em se restringindo ao caso brasileiro, serviria para designar governos de espectros políticos tão diferenciados como o de Vargas na década de 1930 e o do general Geisel

\footnotetext{
${ }^{10}$ Ver Bresser-Pereira (2011b).
} 
nos anos 1970, como se mostrou anteriormente, sem contar a postura mais internacionalizante e com predisposição para associação com o capital estrangeiro de Juscelino Kubitschek, em contraste com o reformismo trabalhista de João Goulart. Todavia, como abstração, o conceito propóe-se captar um padrão de comportamento detectável na condução da ação estatal tanto no sentido lato (com âmbito de abrangência em diversas esferas: tecnológica, educacional, cultural, políticas públicas, dentre outras) e como na formulação da política econômica em sentido mais restrito, o qual permite antever um projeto de longo prazo centrado na industrialização e na modernização do setor primário, implementado com auxílio de medidas governamentais voltadas a incentivar a substituição de importaçóes e a diversificação da produção primária, com prioridade ao mercado interno.

Destarte, mesmo tendo-se presente a observação acima, por desenvolvimentismo designa-se um conjunto de idéias e de práticas efetivas dos governantes o qual sugere estar permeado por uma lógica que se expressa como um projeto de nação. A política econômica governamental não é errática nem apenas reativa aos ciclos ou às flutuaçóes inerentes à conjuntura, mas formulada em consonância a uma pretensão de interferência em seu curso, em busca de uma trajetória previamente definida. Sua gestação histórica foi relativamente lenta; no caso brasileiro, remonta ao final do Império e gradualmente angariou adeptos e só veio a se constituir em prática efetiva nacionalmente a partir de 1930, embora haja experiências regionais anteriores, como João Pinheiro em Minas Gerais (Paula, 2004) e, talvez a mais visível, com o governo Getúlio Vargas no Rio Grande do Sul, em 1928 (Fonseca, 2004). A possibilidade de o conceito abarcar múltiplas situações históricas concretas - fato não inusitado, antes corriqueiro na Economia e demais ciências sociais - não prejudica que se detecte nas diferentes experiências um "núcleo duro" comum, capaz de caracterizar o desenvolvimentismo em suas várias manifestaçóes. Este abrange a defesa: (a) da industrialização; (b) do intervencionismo pró-crescimento; e (c) do nacionalismo, embora este deva ser entendido num sentido muito amplo, que vai desde a simples retórica ufanista conservadora até propostas radicais de rompimento unilateral com o capital estrangeiro (Fonseca: 1989, 2004). Na literatura, na busca de uma maior especificidade e precisão analítica, é comum a referência ao "Nacional-Desenvolvimentismo" para designar o projeto varguista, mais nacionalista e com proposta de incorporação dos trabalhadores urbanos 
pela legislação trabalhista e previdenciária, e o "Desenvolvimentismo-Associado" ou "internacionalizante" iniciado por $\mathrm{Ku}$ bitschek e cuja consolidação teria ocorrido com os governos militares após 1964. Todavia, em quaisquer de seus matizes, o desenvolvimentismo só pode ter sentido se há a percepção, por parte dos agentes econômicos e dos atores sociais e políticos, da existência do subdesenvolvimento. Trata-se, portanto, não de fenômeno somente adstrito ao campo das ideias, mas com contornos de um programa de ação para reverter determinado status quo considerado não desejável; no caso, o atraso ou subdesenvolvimento, com todas as decorrências que podem ser a eles associadas: baixa produtividade, desperdício de recursos, miséria, disparidades regionais e dependência externa.

Entendido dessa forma, quer-nos parecer que não haveria impedimento $a$ priori para que o ideário desenvolvimentista voltasse à cena, uma vez que as próprias condiçôes históricas que lhe originaram não foram superadas. Sua viabilidade, todavia, mesmo com as necessárias conformaçóes a uma nova realidade, a qual the poderia sugerir uma nova forma, não prescinde da exigência de que haja consciência e disposição por parte das elites dirigentes de implementar um conjunto de mudanças. Este, por suposto, não brota- ria espontaneamente ou, per si, como resultado de mecanismos automáticos de mercado; exigiriam ações indutoras, portanto fruto de decisóes políticas. Esta politização da economia, em substituição aos mecanismos normais de mercado, mas sem necessariamente chocar-se com ele ou propor extingui-lo - posto que se trata de desenvolvimento capitalista afasta o desenvolvimentismo do liberalismo em todos seus matizes, inclusive do neoliberalismo (a lembrar a oportuna observação de Michel Foucault, para quem este, menos que suprimir o Estado, revela-se como uma prática governamental voltada a impor a regulaçáo do mercado como princípio regulador da sociedade). Na justificaçáo de si mesmo, como toda boa ideologia, o desenvolvimento torna-se variável necessária - e, em versóes mais radicais, suficiente - para se atingir a um fim almejável. No limite, este se constituiria na razão de ser do próprio governo, a qual aponta para uma utopia a ser construída e permeada de valores de forte apelo, como igualdade, racionalidade, justiça social e soberania. $\mathrm{Na}$ ideologia desenvolvimentista, o desenvolvimento justifica-se a si mesmo.

Assim, sem a presença de intenção deliberada de políticas voltadas a um fim explícito e de um pacto político capaz de lhe dar sustentação, dificilmente 
se pode falar em desenvolvimentismo ${ }^{11}$. Para sua consecução, exige-se a existência de classes, segmentos ou setores sociais com disposição e capacidade para articular um pacto de longo prazo em torno de um programa mínimo quanto a fins, embora possa haver dissensão quanto a meios e a velocidade de implementação das políticas. É visível, no caso brasileiro do século XX, que o ideário desenvolvimentista expressava um consenso sem eliminar pontos de conflito (v. g., distribuição de renda, reforma agrária, articulaçáo com o capital estrangeiro). Todavia, a crença no desenvolvimento como alternativa para o país abarcava desde setores empresariais favorecidos pelos incentivos diretos e indiretos do Estado e ideólogos conservadores que viam no crescimento um amortecedor dos conflitos sociais até sindicalistas adeptos de conquistas salariais e direitos, sem contar os defensores de um marxismo mecânico que viam no desenvolvimento das forças produtivas e no planejamento uma forma de abreviar o caminho rumo ao socialismo.

Destarte, o retorno do desenvolvimentismo, por sua complexidade como fenômeno histórico, apesar de não descartável como possibilidade, exige algumas qualificações. Mas antes faz-se mister o retorno à conjuntura para investigar mais de perto a primeira questáo inicialmente formulada, sobre as condiçōes permissivas à manutenção da tendência de crescimento nos últimos anos e aos prováveis percalços que poderão antepor-se como seus fatores limitantes num futuro próximo.

\footnotetext{
${ }^{11}$ As mudanças ocorridas no governo Lula e as dificuldades de se afirmar claramente a existência de um projeto desenvolvimentista são objeto de debate hoje não só no meio acadêmico e empresarial, mas também na mídia e, com isso, aparecem expressóes para designar didaticamente o fenômeno. Por exemplo, Freire (2011, B4) refere-se à "virada 'neodesenvolvimentista' de Lula" e o qualifica
}

como "desenvolvimentismo acidental", assinalando que, com a crise de 2008 e o recuo dos bancos privados na concessão de crédito imobiliário e à indústria, o bancos estatais chegaram a responder por $80 \%$ do aumento de estoque de crédito; no final de 2011, os bancos públicos perfaziam 43,5\% dos empréstimos.

Claro que essa atitude ágil do governo brasileiro de impedir
o aprofundamento da crise
evidencia preocupação com o crescimento, mas sempre resta a indagação se cabe interpretá- la como vinculada a um
à demanda agregada, as quais são aceitas pelo saber econômico convencional e implantadas mesmo por governos conservadores. projeto desenvolvimentista, posto que política anticíclica, ou seja, resposta a uma conjuntura adversa. Por isso, a rigor, "desenvolvimentismo acidental" é uma contradição em termos, pois confunde projeto de longo prazo com medidas tópicas de fomento 


\section{3_O desempenho recente da economia brasileira em uma perspectiva de longo prazo}

Em uma perspectiva de mais longo prazo $^{12}$, uma análise da economia política do desenvolvimento brasileiro pode partir $\mathrm{da}$ constatação de que, no século XX, o Brasil foi um exemplo típico da experiência latino-americana de modernização, marcada pela presença de avanços econômicos, embora incapazes de equacionar de forma satisfatória o problema da desigualdade na distribuição da renda, riqueza e poder. Entre o final dos anos 1940 e o início da década de 1980, o país transformou radicalmente sua estrutura produtiva e social. O processo de industrialização redundou no fato de que o Brasil chegou a ser a oitava economia do mundo em termos do tamanho da renda e um dos dez maiores parques industriais (Palma 2007, 2011). Em paralelo, experimentou-se uma intensa urbanização e integração de um território continental de 8,5 milhóes de quilômetros quadrados. A renda cresceu $7,3 \%$ ao ano ou $4,5 \%{ }^{13}$ ao ano em termos per capita. Todavia, tal crescimento foi alicerçado em um padrão de financiamento fortemente dependente da utilização de fundos públicos e recursos externos. Além da fragilidade financeira, o desenvolvimento brasileiro revelou-se incompleto, porque incapaz de gerar uma maior homogeneização social.
Nos anos 1970, enquanto o mundo enfrentava os ajustes recessivos gerados pelos choques externos das crises do petróleo e da flexibilização dos regimes cambiais, o Brasil acelerava sua estratégia desenvolvimentista, com base em financiamento externo propiciado pelo ciclo de liquidez da reciclagem dos petrodólares. Com a crise da dívida externa, e a fragilização financeira do setor público, a inflação passou da já elevada média de $30 \%$ ao ano nas décadas anteriores para níveis superiores a $2.000 \%$ ao ano, a partir da segunda metade dos anos $1980^{14}$. Desde então a economia experimentou diversos ciclos curtos e instáveis de crescimento, de modo que entre 1981 e 2003 , a renda per capita expandiu-se a uma taxa média de $0,23 \%$ a.a., ou seja, cerca

\footnotetext{
${ }^{12}$ Sobre o desempenho da economia brasileira em uma perspectiva comparada ver, dentre outros, Barro e Sala-iMartin (2003), Goldman Sachs (2007) e Maddison (2007).

${ }^{13}$ A média da variação do PIB per capita calculado a partir da série a preços constantes (R\$2011) para o período 19471980 é de 4,45\%. A variação do PIB a preços constantes de 2011, no mesmo período, é de 7,34\%. Cálculos próprios com
}

base em: www.ipeadata.gov.br, último acesso em 18/05/2012.

${ }^{14} \mathrm{~A}$ inflação média do período $1945-1979$ foi de $29,52 \%$, com a mediana de $24,51 \%$. Incluindo-se o ano de 1980, tal média chega a $31 \%$. Nos anos de 1989 e 1993 a inflação acumulada ultrapassou os $2000 \%$. Cálculos próprios com base nos dados do IPEADATA. Série utilizada: IGP-DI - geral - centrado - fim período. Ver: www.ipeadata.gov.br, último acesso em 18/05/2012. 
${ }^{15}$ Cálculos próprios com base em: www.ipeadata.gov.br, último acesso em 18/05/2012.

${ }^{16}$ Ver Arida \& Resende (1985). de 1/20 do ritmo verificado entre 1947 e 1980, que fora de 4,45\% a.a. ${ }^{15}$. Ao longo dos anos 1980 e 1990, foram implementadas diversas tentativas de estabilização econômica. Para enfrentar a inércia inflacionária, típica de economias altamente indexadas ${ }^{16}$, os "choques econômicos" vinham acompanhados da introdução de elementos não convencionais, como o congelamento de preços, salários e ativos financeiros, a desindexação total ou parcial da economia e as reformas monetárias. Em cada tentativa fracassada, ampliava-se a instabilidade econômica e institucional, colocava sob tensão os ganhos políticos da redemocratização (Belluzzo e Almeida, 2002, Carneiro, 2002, Giambiagi et al., 2004).

As políticas monetária e fiscal contracionistas, motivadas pelos ditames da estabilização, especialmente em um ambiente marcado por uma série de choques externos adversos - as crises financeiras na segundametade da década - contribuíram para a constituiçáo de ciclos curtos de crescimento (Williamson, 2002, Goldstein, 2003). Com o Plano Real verificou-se, inicialmente, um ganho real de renda dos trabalhadores assalariados das regióes metropolitanas que, todavia, foi perdido entre 1998 e 2002. Em uma perspectiva mais longa, e considerando o rendimento real dos assalariados da Grande São
Paulo, é possível verificar a tendência de queda da renda nos anos 1990. Isto ocorreu a despeito das evidências de que a década de 1990 trouxe um incremento não desprezível da produtividade (Goldman Sachs, 2007).

É importante lembrar que há mais de uma década o debate sobre os rumos da economia brasileira, em geral, e sobre a política econômica, em particular, tem se concentrado na dificuldade de o país retomar o crescimento de forma sustentável. Se, por um lado, o Plano Real foi capaz de debelar um processo crônico de descontrole inflacionário, por outro, a adoção da âncora cambial e a política de juros elevados geraram o acúmulo de sensíveis desequilíbrios de estoques nos fronts externo (Ministério da Fazenda, 2011) e fiscal. A gestão destes em um contexto de reversão no quadro de liquidez financeira internacional, que fora um dos pressupostos para a estratégia de estabilização e "crescimento com poupança externa", marcou a segunda fase do Real - após a desvalorização cambial do início de 1999. Da mesma forma, a tutela do FMI e a implantação de um novo regime de políticas fiscal, monetária e cambial foram definindo os marcos da política econômica perseguida desde então.

A euforia da estabilização com algum crescimento dos primeiros anos, que 
garantiu a base para a reeleição do presidente Fernando Henrique Cardoso, foi dando lugar à estagnação econômica, à deterioração do mercado de trabalho e ao aprofundamento dos passivos fiscal e externo. É nesse contexto sócio-econômico que ocorreu a eleição do presidente Luís Inácio Lula da Silva. Tendo de administrar uma profunda crise, potencializada pelas incertezas da transição política, o novo governo optou, inicialmente, por manter as diretrizes de política econômica herdadas do período anterior.

A análise dos parágrafos anteriores sugere que a combinação da estabilização monetária com reformas estruturais liberalizantes logrou êxito no enfrentamento do quadro de inflação crônica do país e, em certa medida, na modernização da estrutura produtiva. Todavia, às vésperas das eleições de 2002, o Brasil havia acumulado significativos desajustes nos seus estoques de dívida pública e externa. A dívida líquida do setor público já estava acima de $50 \%{ }^{17}$ do PIB, tinha seu prazo de maturação encurtado cada vez mais (com um giro médio inferior a três anos), apresentava um custo de carregamento de cerca de $8 \%$ do PIB (juros nominais sobre a dívida) e terminou o ano de $2002 \mathrm{com}$ um perfil de indexação em que os títulos atrelados à variação cambial respondiam por $1 / 3$ da dívida total. Ademais, as incer- tezas associadas ao processo eleitoral fizeram com que a taxa de câmbio disparasse, com uma desvalorização nominal de 60\% entre janeiro e outubro de 2002 . O pass-trough cambial operou de forma rápida, e tanto a inflação anualizada quanto as expectativas de inflação futura sinalizavam uma trajetória explosiva. Havia um temor generalizado na volta da indexação e no descontrole macroeconômico (Williamson, 2002, Goldstein, 2003, OECD, 2009, IPEA, 2009a).

Qualquer novo governo que assumisse em tais condiçóes muito provavelmente teria como prioridade, ao menos no curto prazo, o retorno à "normalidade", mesmo que isso implicasse na adoção de medidas fiscais e monetárias fortemente contracionistas. No caso concreto do Brasil, o governo recém eleito contava com uma significativa desconfiança do mercado financeiro internacional. A campanha eleitoral havia acirrado os ânimos políticos. Isto levou o então candidato de oposição a uma intensa busca de apoio junto ao setor privado. Símbolo disso foi a elaboração, na reta final da campanha, da "Carta ao Povo Brasileiro", uma afirmação de compromissos com a manutenção da estabilidade econômica e o respeito aos contratos. Observadores contemporâneos passaram a observar que a chegada ao poder do principal líder

\footnotetext{
${ }^{17}$ As informaçōes estatísticas primárias deste e dos parágrafos subsequente são provenientes de OECD (2009), Ministério da Fazenda (2010 e 2011) e IPEADATA (www.ipeadata.gov.br, último acesso em 15/05/2012).
} 
da "esquerda" brasileira nas últimas três décadas e, mais importante, da manutenção de um conjunto amplo de políticas e de contratos, representou a consolidação da transição democrática pós-regime militar. No plano econômico, tal continuidade significou uma (terceira) etapa do processo de estabilização iniciado com o Plano Real.

É no contexto de uma transição complexa e em meio às pressóes financeiras geradas pela desconfiança dos credores é que se deve analisar as opçóes e estratégias de "continuidade" a despeito das críticas prévias contra as políticas econômicas do governo Cardoso. A montagem da equipe econômica do governo Lula e o anúncio das primeiras medidas revelaram o esforço de manutenção do status quo. No plano econômico, o enfrentamento da "crise de credibilidade" deu-se pelo aperto na política monetária e fiscal. Com seu conservadorismo inicial, o primeiro governo Lula logrou reverter as expectativas pessimistas, particularmente dos operadores dos mercados financeiros, com impactos positivos sobre a trajetória da inflação e o gerenciamento da dívida pública. Todavia, manteve-se o quadro de crescimento inferior ao verificado na média mundial. A partir de 2003, a conjuntura externa excepcionalmente favorável contribuiu decisivamente para a correção dos desequilíbrios externos e fiscais.

Os resultados em conta corrente passaram a ser superavitários (Ministério da Fazenda, 2010 e 2011), comandados por recordes sucessivos na balança comercial de um déficit médio de US\$ 1,1 bilhão entre 1995 e 2002, passou-se a um superávit acima de US\$ 30 bilhões por ano, na "Era Lula" ${ }^{18}$. A relação dívida líquida do setor público/PIB recuou $^{19}$, tendo o perfil de financiamento melhorado, pela menor exposição à variação cambial e aos títulos

\begin{abstract}
${ }^{18}$ Para se colocar em perspectiva, em 1990 o Brasil exportou US\$31 bilhóes e importou US\$ 21 bilhões. Em 1995, tais montantes eram de, respectivamente, US\$ 47 bilhôes e US\$ 50 bilhôes Em 2002, de, respectivamente, US $\$ 60$ bilhóes e US\$ 47 bilhôes. E, em 2008, de US\$
\end{abstract}

198 bilhôes e US\$ 161 bilhôes.

Assim, a corrente de comércio saltou de US\$ 52 bilhóes para US\$ 359 bilhóes. Neste movimento, nos anos FHC as importaçôes cresceram, em média, 6,2\% a.a., contra os $4,4 \%$ de crescimento das exportações. $\mathrm{Na}$ era Lula, as importaçóes avançaram, em média, 15,6\% a.a.. Todavia, as exportaçóes cresceram de forma ainda mais intensa: $16 \%$ a.a.

${ }^{19}$ Em 2002 este indicador era de $51,3 \%$, chegando a $53,5 \%$ em 2003. Depois de 2004 verificou-se uma tendência de queda, de modo que, em 2008 a DSLP era de $38,8 \%$ do
PIB. Com a crise financeira as projeçôes de mercado são de uma ampliação neste indicador para o período 2009-2001, para algo em torno de $40 \%$ do PIB. Depois de 2012 haveria novo recuo (IPEA, 2009, IMF, 2009a, e Relatório de Mercado Focus, em 06/11/2009 - www.bcb.gov.br). 
pós-fixados e referidos à variação cambial, além do alongamento de prazos. Houve forte queda no risco-país, e os indicadores de solvência externa - que relacionam os passivos contraídos e as exportaçóes e liquidez externa - passivos externos versus reservas internacionais - melhoraram de forma substantiva. A inflação recuou para a casa de $4 \%$ ao ano - menos da metade da média do período 1995-2002 - e o crescimento da renda atingiu o patamar médio de 4\% a.a. (média 2003-2008).

A recuperaçấo de um maior dinamismo em termos de crescimento se deu a partir da exportação, beneficiada pelo crescimento da economia mundial e pela taxa de câmbio mais competitiva depois da mudança no regime cambial, em 1999. Entre 2001 e 2003, a demanda externa apresentou uma contribuição positiva e superior à demanda doméstica, ao passo que, depois de 2004, a expansão do gasto doméstico passou a liderar o crescimento. No ciclo virtuoso que então se inaugurou, verificou-se uma sensível recuperação do emprego, da massa real de rendimentos do trabalho e do crédito (OECD, 2009, IPEA 2009a e 2009b, e Ministério da Fazenda, 2010 e 2011). Com isso, o consumo das famílias passou a se expandir em um patamar sensivelmente superior ao verificado nos anos anteriores. A formação bruta de capital, quando se considera o indicador trimestral, passou a apresentar o melhor desempenho em mais de duas décadas. $\mathrm{O}$ crescimento econômico, com geração líquida positiva de postos de trabalhos formais - e que, por isso mesmo, contribuem com o financiamento previdenciário - fez com que, depois de muitos anos, o défcit previdenciário se estabilizasse ${ }^{20}$. A dívida pública (líquida e como proporção do PIB) recuou de 53,5\% em 2003, para 38,8\% em 2008, com resultados correntes cada vez melhores, dado que o déficit nominal, que inclui o pagamento de juros, passou de $6,9 \%$ do PIB, em 1997, para $1 \%$ do PIB, em 2008 (Banco Central do Brasil, 2008 e 2009b, IPEA, 2009a).

Às vésperas do agravamento da crise financeira global, no último trimestre de 2008, o Brasil já deixava para trás a impressão de ser um BRIC de segunda linha, e apontava para um crescimento que poderia ter chegado a $6 \%$ ao ano, não fosse a perda de dinamismo dos últimos três meses do ano (Banco Central do Brasil, 2009b). Ainda assim, ao longo

$\begin{array}{ll}{ }^{20} \text { Em 2000, o déficit da } & \text { PIB. O orçamento de } 2010 \\ \text { Previdência Social era de } & \text { projeta um déficit de } 1,17 \% . \\ 0,85 \% \text { do PIB, subindo a mais } & \text { É importante notar que, entre } \\ \text { de } 1,7 \% \text { do PIB no triênio } & \text { 2000 e 2009, mais do que } \\ 2005-2007 . \text { Contudo, em } & \text { triplicaram, de cerca de R } \$ 50 \\ \text { 2008, ele recuou para 1,25\% } & \text { bilhóes para um pouco mais } \\ \text { do PIB e, em 2009, a despeito } & \text { de R } \$ 150 \text { bilhóes (Ministério } \\ \text { da crise, chegou a 1,36\% do } & \text { da Fazenda, 2010). }\end{array}$


do ano de 2009, o dinamismo do mercado interno e os efeitos positivos das políticas contra-cíclicas - expansão do crédito, em um contexto de taxas de juros em trajetória de queda ${ }^{21}$, e diversos estímulos fiscais - garantiram uma reversão do quadro de deterioração do nível de atividades e do mercado de trabalho que se seguiu ao ápice da crise, em setembro de 2008 (Banco Central do Brasil, 2009b). No ano de 2009, verificou-se uma pequena contração do PIB, seguido de forte recuperação em 2010 e a perspectiva de um retorno a taxas mais modestas, a partir de 2011. A inflação, por sua vez, tem se situado dentro dos limites fixados pelo Sistema de Metas (Ministério da Fazenda, 2011).

Portanto, ao final da primeira década do século XXI, a economia brasileira revela sinais de amadurecimento e vitalidade que estão surpreendendo mesmo os analistas mais otimistas sobre as perspectivas do país (IPEA, 2009a, OECD, 2009). Uma evidência neste sentido está no fato de que, em meio a uma crise econômica que tem sido apontada como a mais grave desde 1929, as principais agências de rating elevaram o status do Brasil para grau de investimento (investment grade). Tal fato vai ao encontro das análises de órgãos multilaterais, analistas de mercado e acadêmicos, que revelam a resiliência da economia diante dos impactos da crise financeira global (IMF, 2009b, Unctad, 2009).

Neste sentido, a aposta dos economistas do Departamento de Pesquisa do banco Goldman Sachs ${ }^{22}$, que incluíram o Brasil no rol das principais economias emergentes no século XXI, junto com China, Índia e Rússia, consagrando o acrônimo "BRIC", parece estar se concretizando. Após a sugestão do Goldman Sachs, vários analistas ${ }^{23}$ se mostraram cé-
${ }^{21}$ Em outubro de 2009 , a
taxa real de juros era de 5,4\%.
Na média 2006-2009 ela foi
de 7,4\%; entre 2004 e 2005,
era de 11,5\%; entre 2000 e
2003, 14,9\%; e, entre 1996 e
1999, 18,4\% ("O Brasil Saindo
da Crise", apresentaçáo do
Diretor do Banco Central
do Brasil, Mário Torós, em
outubro de 2009 - http://www.
bcb.gov.br/?APRESPRONUNC, acesso em novembro de 2009).

${ }^{22}$ No começo dos anos 2000, economistas do Departamento de Pesquisa do banco Goldman Sachs introduziram no jargáo financeiro o acrônimo BRICs (de Brasil, Rússia, Índia e China) para designar quatro países cujo potencial de crescimento ao longo do século XXI tenderia a alterar
a configuração da economia mundial. Desde entâo, a atenção de acadêmicos, analistas de mercado e tomadores de decisão nas esferas oficial e privada tem se concentrado, cada vez mais, nas potências emergentes do século XXI. Mais do que uma promessa, a ascensão dos BRICs, dos "Next Eleven", e a recuperação de

\author{
um importante dinamismo \\ econômico no conjunto dos \\ países periféricos, sinalizavam \\ para uma nova conformação \\ do fenômeno da globalização, \\ com o aumento do poder \\ relativo da periferia (Goldman \\ Sachs, 2007, National \\ Intelligence Council, 2005 e \\ 2008, Maddison, 2007). \\ ${ }^{23}$ Ver Arestis e De \\ Paula (2008).
}


ticos com a inclusão do Brasil nesta categoria de potência econômica em ascensão. Até porque havia dúvidas justificáveis sobre a capacidade de o país deixar para trás quase três décadas de semi-estagnação e não seria a primeira vez que se frustraria a promessa de superação do subdesenvolvimento e, assim, de alinhamento com os parâmetros de desenvolvimento econômico e social dos países avançados.

Esta caracterização do desempenho recente da economia brasileira à luz da perspectiva histórica precisa ser confrontada com as distintas interpretaçóes dos analistas. Isto é retomado na próxima seção, mantendo-se o eixo de contribuição do presente artigo que é o de tentar identificar se há elementos na experiência contemporânea que façam eco ao desenvolvimentismo pretérito.

\section{4_Considerações finais: retorno ao desenvolvimentismo?}

Não há dúvidas de que hoje há sinais mais nítidos de crescimento da economia brasileira em comparação com alguns anos atrás. Isto levou autores como Erber (2011) assinalarem que no governo Lula coexistem duas “convençōes' ou visóes de mundo, uma "institucionalista restrita", de caráter mais ortodoxo, e outra denominada por ele de "neodesenvolvimentis- ta", ambas com "núcleos duros analíticos distintos (...), portanto, ontologicamente conflitivas" (p. 53). Todavia, a despeito dos sinais da conjuntura, vários autores apontam para as dificuldades de uma retomada mais consistente e robusta sem que o país enfrente alguns problemas crônicos, como a crise da previdência, a alta carga tributária e o assistencialismo, por exemplo. Esses se aguçaram após o fim do regime militar, com a universalização de políticas públicas consagrado pela Constituição de 1988, implementada na década de 1990 e ampliada pelo governo Lula. Autores como Pinheiro e Giambiagi (2006) ilustram este ponto de vista. Em sua interpretação, os programas voltados à redistribuição de renda, ao invés de colaborarem para o crescimento, o dificultam: "o modelo de aumento simultâneo do gasto público e da carga tributária que caracterizou a economia brasileira em 1991-2005 (...) reduz a eficiência e o potencial de crescimento" (p. XV). O país - a exemplo de outros da América Latina - apresentaria propensão histórica ao populismo e ao assistencialismo; todavia, este não colabora para melhorar a distribuição de renda - ao contrário, é empobrecedor (p.60). Para tanto, apoiam-se em autores como Ricardo Paes e Barros, autor de parábola segundo a qual "se um helicóptero jogasse dinheiro do céu, o ato 
poderia ter mais eficácia para diminuir a pobreza do que muitos gastos ditos sociais que o país faz" (p.77), e Adelman (2000), para quem transferências compensatórias são uma alternativa cara e pouco eficazes para encaminhar uma solução duradoura às desigualdades sociais.

Para esses autores, que exemplificam uma parcela importante do pensamento contemporâneo sobre este conjunto de temas, o principal fator explicativo do crescimento no período mais recente é a estabilidade econômica, ou seja, o fato de o governo Lula, a despeito do assistencialismo, ter mantido as linhas gerais da política econômica de matiz ortodoxo do governo F. H. Cardoso (metas de inflação, altas taxas de juros, câmbio valorizado, superávit primário). Este argumento, não obstante, deve ser visto com precaução, à luz dos dados mais recentes, principalmente relativos à demanda interna. De um lado, não há o que questionar quanto à dificuldade de compatibilizar crescimento econômico e retomada de investimentos, públicos e privados, de um lado, e a permanência do descontrole inflacionário presente na economia brasileira na década de 1980 e controlado a partir do Plano Real. Todavia, se a instabilidade macroeconômica apresenta correlação negativa com crescimento - configurando-se como um fator impeditivo, como é razoável supor à luz de diferentes modelos teóricos e experiências históricas -, daí não se segue que per si consiga explicar o desempenho mais recente e o cenário positivo delineado por vários analistas para o Brasil para os próximos anos, principalmente sua posição relativa no contexto internacional a partir da crise de setembro de 2008, bastante confortável em comparação com outros países. No caso, tudo sugere que as medidas "assistencialistas" não têm sido inócuas, pois vêm apresentando impacto não desprezível na redução da pobreza e na alteração da distribuiçấo de renda, como se mostrou anteriormente; e estas, ao contrário de barrar o crescimento, têm-se mostrado como fator propulsor. Nessa direção também argumenta Soares (2010), para quem a queda gradual e consistente do coeficiente de Gini entre 1995 e 2006 se deve a uma série de políticas de transferências e também de aumento do salário mínimo, revertendo uma tendência histórica que, se mantida por mais tempo e incrementada por outras medidas, como tributárias, de diminuição das desigualdades raciais, regionais e educacionais, poderiam levar o país a um patamar semelhante a alguns países hoje considerados como de ótimo padrão de distribuição.

Em vista disso, é bastante discutível associar a conjuntura da última déca- 
da no Brasil a ciclo econômico populista, pelo menos à luz dos modelos de diversos autores que se debruçaram sobre o tema, mesmo afinados com o mainstream. Neste sentido, vale lembrar a definição mais difundida e pela ortodoxia de populismo econômico, a de Dornbusch e Edwards (1989, p. 9). Para estes,

"a policy perspective on economic management that emphasizes economic growth and income redistribution and deemphasizes the risks of inflation and deficit finance, external constraints and the reaction of economic agents to aggressive nonmarket policies".

Outros autores, como Diaz-Alejandro (1981), Sachs (1989), e Bresser-Pereira (1991, 2006), embora sob diferentes approaches, recorrem a argumentos semelhantes: a partir da concepção de uma curva de Philips negativamente inclinada de curto prazo, sustenta-se que os governos populistas ignoram as restriçóes macroeconômicas, como o combate à inflação e ao déficit público, e optam pelo crescimento acelerado a curto prazo, normalmente alimentado por políticas ativas de sustentação da demanda agregada, aumento de salários, redução de carga fiscal e juros baixos. Daí um ciclo, pois num primeiro momento a economia cresce e o governo se torna popular, mas o brilho é fugaz: lo- go os gargalos e desequilíbrios começam a aparecer: déficit público, desequilíbrio no balanço de pagamentos, mais inflação - a exigir um ajuste ainda mais drástico do que o inicial, "cujos custos suscitam a questão sobre se não será pior a cura do que a própria doença" (Díaz-Alejandro (1981, p. 75).

Nossa análise da "Era Lula" sugere que, não obstante o carisma de seu titular e de alguns arroubos midiáticos, seu governo afasta-se completamente do hard core da definição de populismo daqueles autores $^{24}$. Todos estes registram como fase inicial de seus modelos medidas expansionistas, muitas vezes drásticas, acompanhadas de rejeição a políticas de estabilização. Pode-se claramente concluir que é nesta primeira fase que o populismo econômico se revela, na convicção do governo de que pode enfrentar a situação com a referi-

$\begin{array}{ll}{ }^{24} \text { Esta análise se restringe } & \text { americanos. Convém assinalar } \\ \text { ao conceito de "populismo } & \text { que esses autores, nos mesmos } \\ \text { econômico", a partir da } & \text { trabalhos supracitados, } \\ \text { própria definição dos autores } & \text { embora estabeleçam } \\ \text { aqui abordados, com o } & \text { uma relaçáo teórica entre } \\ \text { propósito de com eles poder } & \text { populismo econômico e } \\ \text { dialogar. Foge ao escopo } & \text { político, normalmente } \\ \text { deste trabalho a discussão } & \text { defendem que, na prática, a } \\ \text { em torno de populismo } & \text { relaçáo entre ambos não é } \\ \text { político, também presente na } & \text { necessária, de maneira que } \\ \text { controvérsia sobre a mesma } & \text { em uma experiência histórica } \\ \text { conjuntura, tanto no Brasil } & \text { particular possam estar } \\ \text { como em outros países latino- } & \text { dissociados. }\end{array}$


da "virada" pró-crescimento acelerado e acompanhado de distribuição de renda, ao invés de optar por políticas restritivas. Em síntese: populismo econômico, para todos os autores, é sobretudo um padrão de comportamento, muitas vezes culturalmente arraigado - ou "embedded", como na tradição institucionalista - o qual, sob determinadas condiçôes políticas permissivas, manifesta-se na formulação da política econômica. Como é por demais sabido, o governo Lula, em seus primeiros anos, não só optou por uma política monetária e fiscal restritiva, como, neste aspecto, representou muito mais continuidade que rompimento com relação ao governo anterior. Em termos de política social, optou pelo gradualismo, apostando mais no longo prazo que no brilho fugaz apontado pelos modelos: elevação paulatina do salário mínimo e dos programas de transferência de renda. Mesmo o afrouxamento da política monetária capitaneado pelo Banco Central, em seu segundo mandato, seguiu a uma comedida estratégia, mesmo que às custas de um crescimento mais nítido a curto prazo. Esta combinação de política econômica restritiva e gradual redistribuição de renda aproxima-se mais do padrão clássico da social-democracia européia do pós-Segunda Guerra, de inspiração keynesiana, do que do "ciclo econômico po- pulista" descrito pelos modelos. Assim, as políticas antes denominadas "assistencialistas", a despeito do ganho político que venham a representar, também se afastam do paradigma populista antes mencionado, pois vêm se mostrando relativamente consistentes no tempo. Náo se pode esquecer que uma das características marcantes, exploradas pelos autores antes mencionados, refere-se justamente à ineficácia do "assistencialismo", ou seja, a boa intenção no curto prazo sempre se revela inócua no futuro - postulado tradicional do liberalismo como corolário da defesa do livre mercado e condenação de medidas intervencionistas pró-redistribuição de renda.

Finalmente, tudo sugere ser prematuro afirmar que se trata de uma retomada do desenvolvimentismo como ideologia norteadora de nova fase da economia e da sociedade brasileiras, apesar dos sinais visíveis da retomada de uma trajetória de crescimento, dos bons fundamentos macroeconômicos (mesmo com problemas a enfrentar, como a ainda baixa formação bruta de capital; a apreciação do Real; o retorno dos déficits em conta corrente; as pressóes especulativas nos mercados de renda fixa, renda variável e derivativos; a persistência da indexação de preços, provocando a tendência manutenção da inflação em patamares superiores ao 
da média mundial; dentre outros) e do incremento do consumo de parte da população até então à margem da demanda doméstica. $\mathrm{O}$ desenvolvimentismo, para se firmar tanto como ideologia hegemônica e, daí, como prática efetiva, supóe um relativo consenso sobre a natureza e a profundidade da política econômica como indutora náo só de investimentos em áreas prioritárias, mas da ação estatal nas demais esferas de abrangência - como educação, tecnologia, mercado de trabalho e políticas sociais, dentre outras -, de forma a forjar um projeto com coerência interna entre fins, meios e instrumentos para viabilizá-los. Supóe, portanto, um pacto político capaz de lhe dar sustentação, ou seja, agentes econômicos, classes e segmentos sociais dispostos a pactuar uma agenda mínima. Apesar de se ter avançado nessa direção nos últimos anos e a crise internacional vir também colaborar neste sentido, não há como fugir da constatação realista de que tudo sugere ser algo não muito claro de se vislumbrar em um horizonte mais próximo. 


\section{Referências bibliográficas}

ADELMAN, I. "Fifty years of economic development: what have we learned?", Conferência Anual sobre Desenvolvimento, Banco Mundial, 2000.

ANDERSON, P. Um Balanço do Neoliberalismo. In: SADER, E., Gentili, P. (orgs.) Pósneoliberalismo: as políticas sociais e o Estado democrático. Rio de Janeiro: Paz e Terra, 1995.

ARESTIS, P., DE PAULA, L.F (editors). Financial Liberalization and Economic Performance in Emerging Countries. Palgrave Macmillan, 2009.

ARIDA, P., RESENDE, A. L. Inertial Inflation and Monetary Reform in Brazil. In WILLIAMSON, John (ed.). Inflation and Indexation: Argentina, Brazil and Israel. Boston: MIT Press, 1985.

BANCO CENTRAL DO BRASIL. Relatório anual 2008. Banco Central do Brasil: Brasília, v. 44,2008 .

BANCO CENTRAL DO BRASIL. Relatório de estabilidade financeira - maio/2009. Banco Central do

Brasil: Brasília, v. 8, n. 1, 2009a.

\section{BANCO CENTRAL DO} BRASIL. Relatório de Inflaçâo setembro/2009. Banco Central do Brasil: Brasília, v. 8, n. 1, 2009b.

BARRO, R. J., SALA-I-MARTIN,

X. Economic Growth, $2^{\text {nd }}$ edition.

Cambridge, MA: MIT Press, 2003.

BELLUZZO, L. G. M. \&

ALMEIDA, J. S. G. Depois da

Queda. Civilização Brasileira, 2002

BELLUZZO, L. G. Um novo estado desenvolvimentista? Le Monde Diplomatique Brasil, ano 3, n.27, p. 4-5, 2009.

BRESSER-PEREIRA, L. C. (org.)

Populismo Econômico: Ortodoxia, Desenvolvimentismo e Populismo na América Latina. São Paulo: Nobel, 1991.

BRESSER-PEREIRA, L. C.“O

Novo Desenvolvimentismo e a Ortodoxia Convencional".

São Paulo em Perspectiva, 20(1): 2006. p. 5-24.

BRESSER-PEREIRA, L.

C. "Crônica do Novo-

Desenvolvimentismo e sua

Macroeconomia Estruturalista”, 2011a (manuscrito).
BRESSER-PEREIRA, L. C. From the National-Bourgeoise to the Dependency Interpretation of Latin America. Latin American Perspectives, Issue 178 - v. 38, n. 3, May, p. 40-58, 2011b.

CARdoso JR., J. C. Para a Reconstrução do Desenvolvimento no Brasil; eixos estratégicos e diretrizes de politica. São Paulo: HUCITEC, 2011.

CARNEIRO, R. Desenvolvimento em Crise: a economia brasileira no último quarto do século $X X$. São Paulo: Unesp, 2002.

CARVALHO, F. C. Lula's Government in Brazil: A New Left or the Old Populism? In: ARESTIS, P., SAAD-FILHO, A. (Editors). Political Economy of Brazil: Recent Economic Performance. Palgrave Macmillan, 2007.

CERVO, Amado Luiz. "A construção do modelo industrialista brasileiro". DEP Diplomacia Estratégia Politica, n.10, p. 75-87, 2009.
DIAZ-ALEJANDRO, F. C. "Southern Cone Stabilization Programs". In: Cline, W. e Weintraub, S. (ed) Economic Stabilization in Developing Countries.Washington, D.C.: The Brooking Institution, 1981.

DORNBUSCH, R. e EDWARDS, S. The Macroeconomics of Populism in Latin America, Chicago: The University of Chicago Press, 1989.

DORNBUSCH, R. e EDWARDS, S. "Macroeconomic Populism", Journal of Development Economics, 32(2): 1990, 247-277.

ERBER, Fabio. "As Convençôes de Desenvolvimento no Governo Lula: um Ensaio de Economia Política”. Revista de Economia Politica, v. 31, n. 1 (121), jan/mar 2011.

FONSECA, P. C. D. Vargas: $o$ Capitalismo em Construção. Brasiliense, São Paulo, 1989.

FONSECA, P. C. D.

Gênese e Precursores do Desenvolvimentismo no Brasil". Pesquisa e Debate, 15(2): 225-256, 2004.

FREIRE, V. T. "A Valsa dos bancos no Brasil”. Folha de São Paulo, mercado, 29/01/2011. 
FURTADO, C. Formação Econômica do Brasil. 15.ed. São Paulo: Nacional, [1959]1977.

GIAMBIAGI, F., CASTRO, L. B., VILLELA, A., HERMANN, J. Economia Brasileira Contemporânea, 1945-2004. Sáo Paulo: Campus, 2004.

GOLDMAN SACHS. BRICs and Beyond. The Goldman Sachs Group (Global Economics Department), 2007 (http:// www2.goldmansachs.com/ideas/ brics/BRICs-and-Beyond.html, capturado em 05/02/2008).

\section{GOLDSTEIN, M. Debt}

Sustainability Brazil and the IMF. IIE WP 03-1. Washington,

D.C.: Institute for International Economics, 2003.

GONÇALVES, R. "Governo Lula e o Nacional-Desenvolvimentismo às Avessas". Revista da Sociedade Brasileira de Economia Politica, n. 31, fev.2012.

Herrlein Jr., Ronaldo. "Estado Democrático e Desenvolvimento no Brasil Contemporâneo: um Ensaio de Economia Política”. Porto Alegre : UFRGS/FCE/ DECON, 2011. Texto para Discussão. Universidade Federal do Rio Grande do Sul, Faculdade de Ciências Econômicas; n. 01/2011).

IMF - International Monetary Fund. IMF Executive Board Concludes Article IV Consultation with Brazil. Public Information Notice (PIN) No. 09/92, July 28, 2009a. Disponível em http://www.imf.org
IMF - International Monetary Fund. World Economic Outlook, October, 2009b. Disponível em http://www.imf.org

IPEA. Brasil em Desenvolvimento: Estado, Planejamento e Políticas Públicas (volumes 1, 2 e 3). Brasília, DF: Instituto de Pesquisas Econômicas Aplicadas, 2009a.

IPEA. Carta de Conjunturajunho de 2009. Brasília: Ipea, 2009b. Disponível em: http:// www.ipea.gov.br/sites/000/2/ publicacoes/cartaconjuntura/ carta07/Carta_junho2009.pdf (último acesso em: 18/10/2009).

MADDISON, A. Contours of the World Economy, I-2030 AD. Oxford University Press, 2007.

\section{MINISTÉRIO DA FAZENDA.}

Economia Brasileira em Perspectiva, $4^{a}$ ed., fevereiro. Brasília, DF: Ministério da Fazenda, 2010 (http://www.fazenda.gov.br/ portugues/docs/perspectivaeconomia-brasileira/link.htm, acesso em março de 2010)

\section{MINISTÉRIO DA FAZENDA.}

Economia Brasileira em Perspectiva - Ediçâo Especial de 2010. Brasília: Ministério da Fazenda, 2011.

MORAIS, L. e SAAD-Filho, A. "Da Economia Política à Política econômica: o Novodesenvolvimentismo e o Governo Lula". Revista de Economia Politica, v.31, n.4 (124), out/dez 2011.

NAKANO, Y. "Catch Up”. Folha de São Paulo, Caderno Dinheiro, 24/01/2010, p. 6, 2010.
NATIONAL INTELLIGENCE

COUNCIL. Global Trends 2025: a transformed world, 2008. (http:// www.dni.gov/nic/NIC_2025_ project.html).

\section{NATIONAL INTELLIGENCE}

COUNCIL. Mapping the Global Future, 2005. (http://www.dni. gov/nic/NIC_2020_project.html).

NOVY, $A$. "O retorno do Estado desenvolvimentista no Brasil". Indicadores Econômicos FEE, v.36, n.4, p.121-128, 2009a.

NOVY, A. "Política e economia, outra vez articuladas". Le Monde Diplomatique Brasil, ano 3, n.27, p. 6-7, $2009 \mathrm{~b}$.

OECD. OECD Economic Surveys - Brazil, volume 2009/14, July. Geneva: Organisation for Economic Co-Operation and Development, 2009.

PALMA, G. Four Sources of 'De-industrialisation and a New Concept of the 'Dutch Disease'. HSRC EGDI Roundtable, May 2007.

PALMA, G. Why has productivity growth stagnated in most Latin American countries since the neo-liberal reforms? Cambridge Working Papers in Economics (CWPE) 1030, July, 2011 (http:// www.econ.cam.ac.uk/dae/repec/ cam/pdf/cwpe1030.pdf, accessed on $20 / 1 / 2012$ ).

PAULA, J. A. de. Adeus ao desenvolvimentismo: a opção do Governo Lula. Belo Horizonte, Autêntica, 2005.
PAULA, J. A. de. "Raízes do Desenvolvimentismo: Pensamento e Ação de João Pinheiro". Pesquisa \& Debate, v. 15, n. 2, 2004, p. 257-282.

PAULANI, L. Brasil Delivery: Razôes, Contradiçóes e Limites da Política Econômica dos Primeiros Seis Meses do governo Lula", in Paula, J. A de. A Economia Política da Mudança. Belo Horizonte, autêntica, 2003.

PAULANI, L. The Real Meaning of the Economic Policy of Lula's Government. In: ARESTIS, P., SAAD-FILHO, A. (Editors). Political Economy of Brazil: Recent Economic Performance. Palgrave Macmillan, 2007.

PINHEIRO, A. C. GIAMBIAGI, F. Rompendo o Marasmo; a retomada do desenvolvimento no Brasil. Rio de janeiro: Elsevier/Campus, 2006.

SACHS, J. D. "Social Conflict and Populist Policies in Latin America”. In: Brunette, R. e Delaringa, C. (eds.) Labor Relations and Economic Performance. Londres: MacMillan Press, 1989.

SICSÚ, J., PAULA, L. F. de, e MICHEL, R. (2005). NovoDesenvolvimentismo: um Projeto Nacional de Crescimento com Justiça Social”. BarueriSP, Manoele e Rio de Janeiro: Fundaçăo Konrad Adenauer, 2005.

SINGER, A. Realinhamento, Ciclo Longo e Coalizóes de Classe. Revista de Economia PUC$S P$, ano 2, n. 4, julho/dezembro 2010. 
SOARES, S. S. D. "O Ritmo da

Queda da Desigualdade no

Brasil é aceitável?” Revista de

Economia Politica, v. 30, n.3 (119), jul/set 2010.

UNCTAD. Trade and

Development Report, 2009.

Geneva: United Nations

Conference on Trade and

Development, 2009.

WILLIAMSON, J. Is Brazil

Next? International Economics Policy Briefs. Washington,

D.C.: Institute for International Economics, 2002.

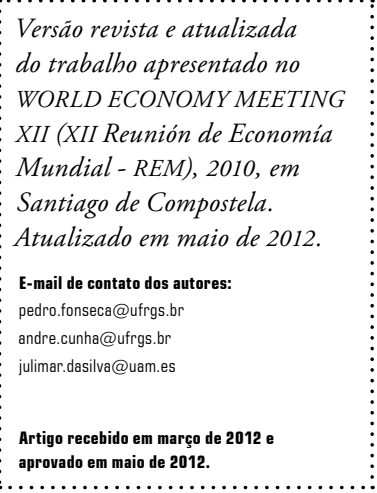


